\title{
Desafíos claves del fortalecimiento de la gestión de los gobiernos subnacionales chilenos en Educación
}

\author{
Sebastián Donoso Díaz \\ Víctor Cancino Cancino
}

\section{Resumen}

Chile necesita profundizar la gestión de los gobiernos subnacionales en educación como una medida estratégica para su desarrollo. Aunque el diagnósticos obre la materia concita apoyo casi unánime, reconociéndose la necesidad de emprender decididamente esta tarea, no se ha avanzado con la velocidad y profundidad requerida, producto de lo cual, los logros en este campo son menores de lo esperado, materia que se constituye en uno de los desafíos principales, permanentes y más relevantes que es la potenciación de la capacidad de gestión de los gobiernos subnacionales. El traba-

jo revisa la noción del Estado y del Gobierno aplicada en el caso chileno, por cuanto los procesos de descentralización, constituyen el marco en el cual se inscriben los desafíos de gestión de los gobiernos subnacionales. Más adelante se establecen algunos criterios de reforma en la gestión del Estado, para avanzar hacia la relación Gobiernos subnacionales y el desarrollo de la educación, aspecto que en lo medular analiza resultados de la reforma educativa chilena y los procesos de gestión del gobierno nacional y subnacionales, identificando aquellos aspectos que requieren de una revisión más detenida, en materias como las políticas de financiamiento del sistema educativo, los resultados en materia de calidad y las dificultades de los procesos de gestión en el actual contexto legal. Finalmente se refuerza el rol de la educación pública como opción de desarrollo democrático, en una visión de liderazgo convocante de los otros agentes que participan en el campo educacional, y con un claro sentido de generador de una identidad local.

Palabras clave: Gestión pública. Procesos de decentralización. Desarrollo de gobiernos subnacionales. Financiamiento de la educación. Educación pública.

- Doctor en Educación. Académico del Instituto de Investigación y Desarrollo Educacional de la Universidad de Talca, Chile y Director del Programa de Magíster en Política y Gestión Educacional y Profesor del Programa de Magíster en Gerencia y Gestión Pública también de la misma Universidad. Es autor de artículos y textos sobre la materia, ha sido consultor del BID, AID y OEI. sdonoso@utalca.cl; Casilla de correos 747, Talca, Chile, teléfono 56-71 - 200253

"Economista y Magíster en Administración de Empresas, con estudios de postgrado en Política Educacional. Es Académico de la Facultad de Ciencias de la Educación de la Universidad Central de Chile y Consultor de la Organización de Estados Iberoamericanos. Anteriormente también fue docente de la Universidad de Talca y Consultor de UNESCO. Ha publicado artículos sobre las materias tratadas. vcancino@ucentral.cl., Teléfono 56-2 - 5826728 
Resumo

\section{Desafios-chave do} fortalecimento da gestão dos governos subnacionais chilenos na educação

Chile precisa aprofundar a gestão dos governos subnacionais em educação como uma medida estratégica para o seu desenvolvimento. Embora os diagnósticos sobre a matéria reconheçam a necessidade de se empreender esta tarefa, não se tem avançado com a velocidade e a profundidade requerida, cujos ganhos neste campo são menores do que o esperado, o que constitui um dos desafios principais, permanentes e mais relevantes que é a potencialização da capacidade de gestão dos governos subnacionais. $O$ trabalho revisa a noção de Estado e de Governo aplicada ao caso chileno, porquanto os processos de descentralização constituem o marco, no qual se inscrevem os desafios de gestão dos governos subnacionais. Mais adiante se estabelecem alguns critérios de reforma na gestão do Estado, para avançar na relação entre governos subnacionais e desenvolvimento da educação, aspecto que, em essência, analisa resultados da reforma educativa chilena e os processos de gestão dos governos nacional e subnacionais, identificando aqueles aspectos que requerem uma revisão mais acurada em matérias como as políticas de financiamento do sistema educativo, os resultados em matéria de qualidade e as dificuldades dos processos de gestão no atual contexto legal. Finalmente, reforça-se a educação pública como opção de desenvolvimento democrático, numa visão de liderança convocante de outros agentes participantes do campo educacional, e com um claro sentido de gerador de uma identidade local.

Palavras-chave: Gestão pública - Processos de descentralização - Desenvolvimento de governos subnacionais - Financiamento da educação - Educação pública

\section{Abstract \\ Key challenges in the strengthening of management of Chilean subnational governments in education}

Chile needs to deepen the management of the subnational governments in education like a strategic measurement for its development. Although the diagnoses build the matter arouses almost unanimous support, recognizing the necessity to undertake this task decidedly, has not advanced with the speed and required depth, product of which, the profits in this field are smaller of hoped, the matter that is constituted in one of the main challenges, permanent and more excellent than it is the involution of the capacity of management of the subnational governments. The work reviews the notion of the State and the Government applied in the Chilean case, inasmuch as the decentralization processes, constitute the frame in which the challenges of management of the subnational governments register. More ahead some criteria of reform in the management of the State settle down, to advance towards the relation subnational Governments and the development of the education, aspect that in central 
analyzes results of the Chilean educative reform and the processes of subnational management of the national government and, identifying those aspects that require of one more a revision prisoner, in matters like the policies of financing of the educative system, the results in the matter of quality and the difficulties of the processes of management in the present legal context. Finally the roll of the public education like option of democratic development is reinforced, in a vision of convoking leadership of the other agents who participate in the educational field, and with a clear sense of generator of a local identity.

Keywords: Public management.

Decentralization processes. Development of subnational governments. Financing of the education. Public education.

\section{Presentación}

La discusión y análisis de la temática del fortalecimiento de la capacidad de gestión de los gobiernos subnacionales es materia relevante en el contexto chileno, dado que se trata de una función que como país se busca y también se necesita profundizar, en razón de los cual concita apoyo desde casi todos los planos, el político, económico, las organizaciones sociales y la sociedad civil. Sin embargo, ante un diagnóstico que reconoce con creces y hace larga data la necesidad de emprender decididamente esta tarea, ya que la actual capacidad de gestión demostrada por estas unidades ha representado más un freno que un aliciente para el desarrollo regional y por ende del país, implicando que muchos de los obstáculos reales en los gobiernos subnacionales en materia de gestión han desalentado algunas de las medidas que se han propuesto como mejoras en este plano, lo que ha dado como resultado menores avances de lo que se debería haber logrado, materia que se constituye en uno de los desafíos principales, permanentes y más relevantes que es la potenciación de la capacidad de gestión de los gobiernos subnacionales.

El estudio del tema implica en lo conceptual revisar la noción del Estado y del Gobierno aplicada en el caso chileno, pero fundamentalmente ello significa revisar la estructura de poder del Estado, por cuanto los procesos de descentralización, constituyen el marco en el cual se inscriben los desafíos de gestión de los gobiernos subnacionales.

En este contexto resulta un hecho significativo que tanto en los mecanismos de diseño como de gestión del Estado chileno se ha tendido a replicar en los gobiernos subnacionales de nivel regional la estructura imperante en el Gobierno central, aunque con funciones algo menos complejas debido a los grados parciales de descentralización y desconcentración que se han implantado.

Lo expuesto da cuenta que de hecho en el diseño e implementación de la política se ha operado con dos facetas que muestran ciertas contradicciones y conflictos aún no resueltos debidamente: Una de ellas se refiere al interés manifiesto por desarrollar los gobiernos subnacionales a escala regional, pero manteniendo algunos mecanismos centralizadores claves en materia de diseño de las políticas, como también en la asignación de los recursos (de todo tipo). La segunda dimensión se refiere al diseño y desarrollo del proceso de descentralización y desconcentración como si fuese un fenó- 
meno homogéneo, es decir empleando un esquema operativo que reconoce las materias referidas al Gobierno nacional -incluyendo en este ámbito el gobierno subnacional de la capital metropolitana- pero por otra parte implica a todos los gobiernos subnacionales como unidades equivalentes y homogéneas en sus necesidades y capacidades, cualquiera sea la región que se localicen, sin establecer mayores distingos acerca de las características particulares de estos últimos Gobiernos subnacionales en sus múltiples aspectos.

Esta última condición implica reforzar una visión uniforme en todos sentido de los gobiernos subnacionales haciendo caso omiso a la pertinencia de las políticas y por ello de los principales instrumentos de gestión empleados por el gobierno en sus distintos niveles, dando cuenta con ello que en Chile -salvo excepciones- no hay un número relevante de políticas propias de los gobiernos subnacionales, como de igual forma, la mayor parte de los instrumentos de gestión son eminentemente genéricos: aplicables a cualquier unidad subnacional sin importar las condiciones del territorio, población, etc.

Por su parte, la situación del sector educación en el país se ajusta sin ningún tipo de esfuerzo a lo descrito. Es más, el plano políti$\mathrm{co}$, los procesos de reforma educativa impulsados a lo largo del siglo XX como en el primer quinquenio del presente siglo, muestran que los gobiernos subnacionales han tenido más bien una participación irrelevante en el desarrollo de este sector, cumpliendo las orientaciones y normativas del gobierno central, salvo un par de intentos fallidos como fueron el Plan de Desarrollo Educacional de la Comuna de San Carlos, que se buscó implementar a inicios de la década de los 40' y que tras un par de años de aplicación parcial debió abandonarse, y el Plan Arica, impulsado veinte años después (de inicios de la década del 60') que corrió igual suerte, acusando problemas de asignación de recursos, entre otros factores, pese al entorno favorable que avalaba impulsar estas iniciativas.

En materia de gestión la experiencia masiva más reciente que es el proceso de traspaso de los establecimientos escolares -incluidos los docentes- a los municipios, ocurrido entre los años 1981 a 1987, situación irreversible a la fecha, que no cambió la visión centralista de la educación, como tampoco implicó la generación de nuevos proyectos educativos de calidad de nivel subnacional, sino por el contrario, producto de una serie de carencias bajo las cuales ha operado este proceso, las que se analizan más adelante, ha generado en algo más de dos décadas de operación mayores impactos negativos que positivos sobre la calidad de la educación, en lo fundamental de la población más vulnerable.

La educación superior es el único nivel del sector educación que ha tenido una experiencia 'exitosa' en materia de desarrollo, producto de cierta autonomía de gestión derivada de la reforma de 1981, que tras el retorno a la democracia, en el año 1990, pudo hacerse efectiva y que además contó con un significativo impulso de recursos públicos y privados. Sin embargo, ello no implica -como se discute más adelante- que exista plena sinergia entre los proyectos universitarios y los gobiernos subnacionales Lo cierto es que la formación terciaria en el caso chileno es un fenómeno social complejo de analizar y que su desarrollo excede la visión subnacional y se inserta con mayor fuerza en los procesos de mundialización. 
El documento que se expone se centra en el análisis del tema con especial atención para el sector educación, buscando precisar algunos de los principales desafíos que enfrentan los gobiernos subnacionales en Chile para fortalecer su capacidad de gestión en pro de cumplir con tareas relevantes referidas al desarrollo del sector. La exposición se desarrolla a partir del análisis de la concepción vigente del Estado chileno y por ende del rol que al respecto cumple el Gobierno nacional, factor clave para comprender el "estado actual del tema" su nivel de desempeño y desarrollo, y la orientación al cambio, línea estratégica en la cual se insertan los gobiernos subnacionales.

En función de lo puntualizado se revisan las tareas emprendidas por los gobiernos subnacionales en el área educacional, tanto en lo que dice relación con las que le competen ante el gobierno nacional, como respecto de aquellas que les son propios en su esfera territorial, en las que se incluye de manera destacada su relación con los gobiernos locales. Para la adecuada comprensión del problema que se analiza, es indispensable detenerse en el peso que representa el sector educación, en la forma cómo se ha organizado el sector, el tamaño de su estructura y la complejidad de sus tareas, como a su vez, en las responsabilidades que le competen y las atribuciones que dispone.

Explicitados estos aspectos se identifican los principales desafíos en materia de "capacidad de gestión" de los gobiernos subnacionales según ámbitos: el referido a la adecuación de las políticas nacionales, el correspondiente a la elaboración de políticas propias para su ámbito de influencia, el referido a los nexos de estas políticas con los gobiernos locales (lo que de paso implica revisar con mayor detenimiento estos aspectos en el plano local), el correspondiente a los mecanismos e instrumentos de gestión, incluyendo los sistemas de control interno y externo, sus indicadores, los criterios de desempeño y otros elementos propios del tema en análisis.

\section{Estado, reforma y Gobiernos subnacionales: precisiones iniciales}

Constitucionalmente el Estado de Chile se define como unitario, y su administración como funcional y territorialmente descentralizada o desconcentrada en su caso. Esta normativa se ha mantenido y adecuado, incluso en la nueva reforma constitucional realizada en el mes de mayo del 2005 recién pasado. De igual forma se establece la importancia de los gobiernos subnacionales al indicarse que los órganos del Estado promoverán el fortalecimiento de la regionalización del país y el desarrollo equitativo y solidario entre las regiones, provincias y comunas del territorio nacional. La visión unitaria del Estado, con un fuerte componente presidencialista, ha sido dominante en los casi 200 años de vida del país, aunque no por ello han desaparecido otras propuestas que no han tenido la fuerza ni acogida para imponerse (CARO, 2003).

Este propósito debe inscribirse en lo que ha sido el proceso de modernización del Estado Chileno en el último cuarto del siglo XX, cuando el Estado de Bienestar (o de Providencia), al que le cupo un papel insustituible en los procesos de desarrollo del siglo en comento, fue objeto de transformaciones de magnitud ante problemas significativos de competitividad y de capacidad para solucionar males endémicos de 
las sociedades nacional, invocándose por muchas agencias financieras multilaterales la necesidad de reducir su tamaño, como punto central de una solución pro mercado que penetró en Chile con fuerza y sin contrapeso - entre otros motivos por la situación dictatorial en la cual se encontraba el país. La distancia permite afirmar que esta propuesta es más ideológica que fundada en evidencia empírica, y que las transformaciones en el marco de la globalización y mundialización requerían de decisiones más reflexivas, profundas y sinérgicas entre los diversos agentes económicos, el mercado y el Estado, desarrollando políticas sólidas y validadas que dieran sustentabilidad a la sociedad y al Estado en un modelo de trabajo mucho más colaborativo del que inicialmente se asumió.

Para el caso chileno la política de los años $80^{\prime}$ respecto de los 90' fue muy diferente. Ciertamente el retorno a la democracia ocurrido a comienzos de 1990 permitió poner freno a una política de reducción sin límites del accionar del Estado en todos los planos (con la Excepción de la defensa nacional), y que incluyó en forma decidida la sincronización de todos los sectores económicos y sociales con el racional propio del mercado, incluyendo previsión social, salud, educación y vivienda. Para el sector educación, algunas de las implicancias más evidentes de esta política, dentro de muchos otros resultados, fue la reducción del presupuesto público del sector en más del $25 \%$ real hacia el final de la década de los $80^{\prime}$, y donde la participación en el PIB se redujo de un $7 \%$ en los años $70^{\prime}$ a un $4,2 \%$ en 1990, incluyendo el gasto público y pri- vado (GONZÁLEZ, 2003, p. 610). Esta política se aplicó de manera paralela a la transferencia de los establecimientos escolares a los municipios, al cambio de las normativas laborales de los docentes y de la política de financiamiento a las escuelas, transformaciones encadenadas a una propuesta de mercado en su sentido más lato que dejaron una honda huella en mala calidad de la educación como lo reportaron los resultados de las pruebas al respecto $(\mathrm{SIMCE})^{\prime}$ aplicadas a los $4^{\circ}$ grados de primaria del año 1988 y las siguientes.

De esta forma una de las primeras tareas del Gobierno en la década de los 90' en Chile implicó detener el proceso de reducción del tamaño del Estado y dio comienzo a una modernización en su accionar que fundamentalmente buscaba regular -con éxito dispar- muchos de los cambios que ya se habían impulsado en materia económica, a saber: disciplina fiscal, control del gasto, manejo de tipo de cambio, liberalización del sistema financiero, apertura a la inversión extranjera, privatización de empresas públicas, y las reformas al Estado, siendo estas últimas posibles de analizar considerando las tres perspectivas analíticas que coexisten respecto de la temática: la administrativa, los cambios institucionales y la reforma democrática (TOMASSINI; ARMIJO, 2002).

El primero de los enfoques se le denomina "administrativo" y es conocido en la actualidad como el de 'gerencia pública', que busca impulsar en la instituciones del Estado la visión del desempeño y de los resultados, su medición, la asignación de estímulos, orientadas al servicio al usuario, que busca

1 EI SIMCE corresponde al Sistema de Medición de la Calidad de la Educación, se traduce en un conjunto de pruebas de lectoescritura, matemáticas y ciencias aplicadas a los $4^{\circ}, 8^{\circ}$ y $10^{\circ}$ grado del sistema escolar. Se aplicó inicialmente los años 1982 a 1984 (bajo la sigla PER) y luego de 1988 en adelante hasta la fecha. 
nuevos diseños institucionales que cambien la cultura de 'entidad monopólica' a diseños más flexibles y horizontales donde la rendición de cuentas y de descentralización y desconcentración de sus funciones. La reforma gerencial del Estado, que proviene de la experiencia de Nueva Zelanda, Irlanda y otras culturas anglosajonas fue adoptada en el país primero como algo formal, aunque en la actualidad se han dado pasos ciertos en esa dirección, no solamente con la creación del Consejo de Alta Administración Pública, cuyo accionar en materia de selección de "gerentes "ha sido menor, pero si en cuanto al perfeccionamiento de los recursos humanos del Estado, donde ha tenido una clara orientación en este plano en la presente década.

Ciertamente para el caso chileno esta tarea ha sido complicada, pues ha debido regular situaciones que estaban ya operando y que eran claramente asimétricas entre oferentes y demandantes, lo que implica "normar" un mercado muy desrregulado, que requería protección a sus beneficiarios. Ello fue posible observarlo con mayor facilidad en la administración de servicios públicos monopólicos, como agua y electricidad, y fundamentalmente con sistema de pensiones y de salud, donde el mercado privado es muy poderoso y se ha opuesto tenazmente a perder parte substantiva de su privilegios, generándose reformas parciales de menor impacto.

En el sector educación esta situación es mucho menos compleja aunque no por ello la tarea está cumplida. Se requiere de adecuaciones de importancia, unas de nivel nacional con repercusiones a nivel subnacional, como la necesidad de reponer la Superintendencia de Educación, aunque con un carácter diferente al jugado anteri- ormente y otras de nivel subnacional que se debaten más adelante y que se refieren al rol de las instituciones responsables de cada sector en el plano señalado.

La segunda perspectiva analítica se refiere al cambio institucional producto de las nuevas demandas sociales de grupos emergentes, desprotegidos o bien insatisfechos, impulsados además por requerimientos tecnológicos, que presionan por una nueva institucionalidad. Se trata de un nuevo equilibrio entre el mercado, el Estado y la sociedad civil, que a partir del tácito e incuestionable peso del mercado, busca revisar y redireccionar sus políticas públicas sin transgredir los equilibrios macroeconómicos fundamentales, cuyo aprendizaje de este principio operativo fue pagado por América Latina a un alto precio. "Las Reformas de tipo gerencial buscan modernizar la gestión de los servicios públicos encargados de ejecutar las políticas gubernamentales, en tanto que el rediseño de las instituciones del Estado tiene por objeto habilitarlo para formular más eficientemente esas políticas" (TOMASSINI; ARMIJO, 2002, p. 26).

Sin embargo, en el caso chileno el fortalecimiento de la capacidad del Estado para satisfacer por si mismo la demanda ciudadana es una temática aún incipientemente discutida, sea porque las leyes 'de amarre' de la época dictatorial aún imponen restricciones al hacer de un Estado más empresarial, como también porque la visión neoliberal de la sociedad y del mercado han desacreditado el accionar directo del Estado como ejecutor de políticas.

En esta materia el Ministerio de Educación de Chile ha buscado mediante la estrategia de programas focalizados es- 
pecíficos alterar el sistema financiero de subvención al estudiante (analizado en secciones siguientes) propio del mercado, con acciones transversales hacia los establecimientos escolares que atiende la población con mayores requerimientos de calidad, reportándoles recursos o financiamiento directo, al respecto destacan entre otros- El programa de "Escuelas Focalizadas", para aquellas que tienen los resultados escolares más bajos, el de "Jornada Escolar Completa", destinado a proveer recursos de infraestructura y equipamiento para los establecimientos que desean ampliar su jornada de trabajo diaria y el de "Liceo para Todos", destinado a apoyar la reinserción en enseñanza secundaria de desertores escolares provenientes de los niveles socioeconómicos más bajos de la población, Todas - ciertamente - iniciativas manejadas centralizadamente por el Gobierno y con un escaso rol desconcentrador.

La tercera perspectiva implica asumir una visión de gobernabilidad sustentada en la democratización del Estado, lo que debe traducirse en capacidad para identificar e interpretar adecuadamente las demandas ciudadanas y traducirlas en políticas según las prioridades alcanzadas en las agendas de debate. Esto significa incorporar las visiones anteriores de reformas al Estado para que éste se desempeñe no sólo como un agente regulador sino también de igual manera como un actor direccionador de las políticas según su capacidad para interpretar y traducir demandas y necesidades en propuestas de acciones. Esta situación implica para el Estado ampliar su ca- pacidad de integrar e integrarse a la sociedad civil, Esta perspectiva no siempre es comprendida en su sentido biunívoco, sino esencialmente se la entiende como el considerar los problemas de los usuarios para buscar soluciones, pero el rol de participación activa de la sociedad civil en la definición de políticas es mucho menos practicado, aunque se le entiende como una condición clave para la adopción de decisiones adecuadas y oportunas.

Asumiendo que en la concepción actual del rol del Estado su principal tarea es la formulación de las políticas públicas con la finalidad de orientar y regular el comportamiento de los distintos agentes económicos y sociales, toda vez que su rol ejecutor está en segundo orden dada la plena competencia de privados o del mercado globalizado, su tarea se compatibiliza en velar por el interés público y los intereses de los diversos grupos, según su grado de deprivación. En razón de lo señalado, las implicancias de este considerando son estratégicas pues se sabe que de la calidad y oportunidad de las políticas públicas dependerá en grado importante la gobernabilidad del país ${ }^{2}$. En el formato del Estado chileno, las competencias esenciales de esta tarea residen en el Estado central, los Gobiernos subnacionales no desempeñan aún un papel relevante que no sea aquel de cumplir con algunas funciones descentralizadas o desconcentradas, representación de autoridades u otras, entre las que pueden estar las de hacer cumplir normativas nacionales (replicar la función del Ministerio en el ámbito subnacio-

\footnotetext{
2 Entendida como la capacidad del Gobierno para articular, ordenar y responder en forma armónica las distintas demandas ciudadanas por desarrollo social y económico, participación y equidad, de forma que pueda continuar gobernando, se entiende bajo principios democráticos si esta es la tipificación de la gobernabilidad.
} 
nal en estas tareas), obtener información y entregarla ordenada para su procesamiento central, quedando claro que el tema del diseño y estructuración de las políticas es una tarea que esencialmente le compete al ámbito central.

\section{Gobiernos subnacionales $y$ el desarrollo de la educación Gobierno nacional, Gobiernos subnacionales y resultados de la reforma educativa}

El accionar del gobierno nacional y por extensión de los gobiernos subnacionales en el campo educacional esta referido al cumplimiento de una tarea central y común del país que es incluir a toda la población en edad escolar en el sistema educativo, labor que puede ser una tarea rutinaria como un desafío de proporciones según el nivel de desarrollo alcanzado. De este primer quehacer, se desprenden dos imperativos claves de gestión: el primero es proveer una educación de calidad para todos y, paralelamente, sentar las bases de construcción y mantención de la sociedad, proceso de socialización que implica legitimar la diversidad a fin de fortalecer la ciudadanía y la democracia.

Las tareas descritas están insertas en las estrategias de implementación de la actual reforma educativa iniciada formalmente a mediados de la década pasada. Se trata de una innovación integral del sistema educa- tivo en sus niveles primario y secundario cuya orientación responde a lo que se conoce como reformas de segunda generación, dirigidas a solucionar los problemas de calidad y equidad de los sistemas educativos.

La actual reforma se inscribe en una historia el siglo XX que suma tantos proyectos de reforma educativa como décadas se cuentan ${ }^{3}$.Lo común de estos procesos es que todas estas propuestas han sido iniciativas del Gobierno central, con escasa o casi nula participación de los gobiernos y autoridades subnacionales, incluso en lo que respecta a las dos iniciativas que tuvieron acento local (Plan San Carlos y Plan Arica) también se produce este fenómeno. La constante en este plano es que el gobierno nacional define y establece los caminos y criterios de traspaso de la responsabilidad, tareas y recursos a los gobiernos subnacionales con una muy baja ingerencia de la sociedad regional y local en estas decisiones.

Por su parte, al igual que lo que acontece con la mayor parte de las reformas educativas, la actual propuesta asume dos lineamientos estratégicos comunes a cualquier realidad, sea nacional o subnacional: primero, el mejoramiento general de los resultados educativos de la población, mediante intervenciones explícitas en el sistema educativo (sean de tipo amplio o focalizadas) y segundo, la actualización de sus competencias para su mejor incorporación al mercado de trabajo.

El hacer educativo desde el año 1990 estuvo marcado al menos por tres aspectos claves: Primero, la ya comentada fuerte reducción del

${ }^{3}$ El siglo fue pródigo en estas materias: en los años 1920 y 1925 se dictan leyes de enseñanza primaria obligatoria que producen la incorporación masiva a las primeras letras de los sectores populares, cuyas cifras de analfabetismo eran cuantiosas (SALAS, 1917), Le sigue la reforma de 1928 y la contrarreforma de 1929, más adelante en la década del 40' el Plan Integral San Carlos y La Reforma de la Enseñanza Secundaria, en los años 60' el Plan Arica y la Reforma de 1965, el proyecto ENU de 1973 y la reforma "inadvertida" del Gobierno Militar de 1981, culminando el siglo con la reforma de 1995-1996. 
presupuesto del sector educación que realizó el Gobierno militar desde el año 1982, al extremo que los recursos que éste le asignó al primer año de ejercicio financiero del Gobierno Democrático (1990) representaron el 72\% del monto total actualizado respecto del valor del año 1982 (GONZÁLEZ, 2003, p. 610). Segundo, como consecuencia de lo anterior, se deterioró en forma sostenido la calidad de la educación, cuyos impactos son generacionales y tardan en revertirse más allá de la inflexión presupuestaria que se produce a partir del año 1991, más aun cuando paralelamente en el año 1981 se produce la gran 'reforma educativa neoliberal pro mercado", cambiando el sistema de financiamiento de la educación pública en todos los niveles; transformando el régimen de contrato y dependencia de los docentes; afectando con ello fundamentalmente su estabilidad y carrera funcionaria (NÚÑEZ, 2003b), y traspasando la gestión de los establecimientos escolares a los municipios. Finalmente, el tercer aspecto es que la reforma de $1981 \mathrm{ge}$ neró un caos 'invisible en el corto plazo' en la gestión financiera (JOFRÉ, 1988) y en la pedagógica. El sistema educativo asumió un modelo de gestión matricial pero sin puntos de control de la intersección, es decir, el Ministerio asume la responsabilidad de materias para las Cuales no dispone del instrumental legal plenamente requerido para responder por esta tareas a nivel de los establecimientos educacionales y, estos últimos pueden operar con criterios diferentes a las orientaciones ministeriales, salvo en algunas materias básicas ${ }^{4}$.

Estos aspectos que siguen hoy presentes, significan que el año 1990 se partió de un diagnóstico del sistema educativo mucho más optimista del que correspondía, lo que explicaría el lento progreso alcanzado a la fecha en aquellas dimensiones educativas que estaban profundamente deterioradas

La educación chilena, al inicio del Gobierno del Presidente Aylwin exhibía logros de importancia, el aumento en la escolaridad promedio de los chilenos y la reducción del analfabetismo. En contraste, el sistema educativo mostraba indicadores críticos en cuanto a la calidad de la educación y la equidad de su distribución. También había fuertes problemas de gestión, ya que la situación de los profesores y los niveles de financiamiento de la educación se habían deteriorado mucho durante la década de los 80. (GARCÍA-HUIDOBRO; COX, 1999, p. 9).

\section{a) Financiamiento del sistema edu- cativo e impactos registrados}

El cambio del sistema de financiamiento de la educación - implantado a partir del añol 198 - por un enfoque mixto de subsidio a la demanda con ciertos factores correctores, trajo consecuencias significativas en la composición de la matricula escolar desde el plano de la dependencia. Antes de iniciado el proceso el sector fiscal reunía el $80 \%$ de la matrícula total, el particular con subvención del Estado el 15\% y el privado sin subvención un 5\%. Cinco años después (1986), el ahora sector municipal (ex-fiscal) se había reducido al $63,1 \%$, el subvencionado se elevaba al $30,8 \%$ y el privado sin subvención seguía en un 5,1\%. Diez años después de la última cifra (1996) el sector municipal agrupaba el $56,5 \%$ de la matrícula, el subven-

\footnotetext{
${ }^{4}$ Es extraño que los autores proclives a la privatización de lo público, que ponderan la eficiencia en la gestión, no se refieran a esta situación "esquizofrénica" del sistema, no resuelta a la fecha (El Ministro de Educación a comienzos de noviembre de 2004 alude a ella), como tampoco consideren el hecho que el Ministerio no dispone de herramientas para sancionar económicamente a los planteles que no cumplen las normativas fundamentales, salvo en situaciones extremas, dos aspectos que una gestión eficiente -mirado desde el mercado-debió haber previsto.
} 
cionado el $33 \%$ y el particular el $8.7 \%$. Al año 2002 los cambios persisten pero cada vez con menor fuerza. El sector municipal reúne el 52,3\%, los subvencionados el $38,1 \%$ y los privados el 7,8\% (COX, 2003, p. 27). El simple ajuste de las cifras da cuenta que los establecimientos municipales redujeron su representación en la matrícula en casi 27 punto porcentuales, gran parte del cual $(23 \%)$ se pasó al sector subvencionado. Sin necesidad de mayores estudios se puede concluir que el sector subvencionado es el gran ganador, en este punto. Ello ha sido enarbolado por alguno sectores como el éxito del proceso de privatización y su posterior validación como proveedores de mejor calidad educacional, argumentación sostenida por aquellos que defienden la gestión privada como un agente que incluso supera las diferencias estructurales, pues fundamentalmente se trata de un tema de incentivos económicos. "El traspaso de los establecimientos fiscales a las municipalidades [ocurrido entre 1981 y 1986] replicó en muchos casos el centralismo a nivel comunal. Estas escuelas en la práctica no compiten entre si por los alumnos. Están ausentes los incentivos para que ello ocurra" (BEYER et al., 2003, p. 187).

Los resultados respecto de la distribución de matrícula por dependencia según decil socioeconómico dan cuenta que en la década de 1990 al año 2000 se ha concentrado la población más pobre en los establecimientos municipales y la más solvente en los privados pagados, ratificando los procesos de exclusión financiera que conlleva este tipo de financiamiento (véase Cuadro $N^{\circ} 1,2$ y 3), lo que en su momento fue señalado también por Hsieh y Urquiola (2002). En el cuadro 3, ordena por decil socioeconómico los puntajes SIMCE. Se aprecia que una elevada proporción de los alumnos que asisten a establecimientos que en promedio son más pobres, provienen de hogares de menores recursos. Por su parte, en el decil más alto de establecimientos, se observa que el $90 \%$ de su matrícula proviene del decil más alto de familias. Es en este grupo donde existe mayor segregación. El mismo ejercicio aplicado a educación básica, arroja levemente más concentración en los establecimientos más pobres, y menor concentración en los deciles más altos.

Este proceso se produjo paralelamente con el incremento de los recursos financieros del sector. El gasto público en educación como porcentaje del PIB pasó del $2,7 \%$ en 1995 al 4,0 en el año 2000, y el gasto privado de 2,1 a a 3, $\%$ (CHILE, 2002, p. 37), y consecuentemente el gasto público en educación como porcentaje del gasto público total se incrementó del 15,3 al 18.1\% (COX, 2003, p. 45). Ilustrativamente, el gasto del Ministerio de Educación que en el año 1995 significó un índice de 124 sobre el mismo ítem del año 1982, se incrementó al valor 204 en el 2000 respecto de 1982 y, en términos absolutos, se tradujo aproximadamente en un $60 \%$ de nuevos recursos en moneda constante respecto del año 1995 (GONZÁLEZ, 2003, p. 610). Este proceso también implicó incrementar el gasto público por alumno en esos años, creciendo respecto de 1995 más de un 40\% en la enseñanza básica y casi un $50 \%$ en la media (CHILE, 2002, p. 41). En síntesis, es claro que la inversión tanto privada como pública del país en educación se incrementó sostenida y significativamente, factor reforzado por el crecimiento de la economía nacional que en la década de los 90'duplicó su valor total, de esta forma el incremento porcentual revertía el bajo gasto en 
educación de las décadas pasadas e incluso superó la tasa histórica de gasto de Chile en educación (7\%) antes de la dictadura militar.

\section{b) Impactos sobre la calidad de la educación}

En materia de los indicadores clásicos de eficiencia interna del sistema educacional las cifras registran una tendencia positiva. La cobertura de la enseñanza básica se estabiliza en un $97 \%$, y la de enseñanza media en el $87 \%$ (CHILE, 2002, p. 25), Por su parte, la deserción en básica y media se eleva, en el primero del 1.7 al $2 \%$ y en la segunda del 6.6 al 8.5 (CHILE, 2003, p. 33), no hay explicaciones convincentes más allá de plantear que las crisis económicas se presentan en el sector educación con cierto rezago, excepto para la educación superior (LASSIBILLE; NAVARRO, 2004, p. 93). Para la enseñanza básica, la tasa de reprobación gira en torno del $3 \%$ en el 2002, y la tasa de abandono escolar en el 1,3\% para los mismos años (CHILE, 2002, p. 77). La situación en la enseñanza media es levemente más positiva en esos años, la reprobación baja al 6,4\% y el abandono al 4\% (CHILE, 2002, p. 78). Finalmente, la tasa de éxito oportuno y éxito total se redujo de manera manifiesta: Para la cohorte 1980 - 1990 la primera era de 37.6 y la segunda de 64,9, mientras que para la cohorte 1992 - 2002 son del 54\% en éxito oportuno y $83.5 \%$ de éxito total. Las implicancias de estos resultados impactan en una reducción del mayor tiempo de inversión del 28,3 al 14,2\% (CHILE, 2002, p. 80).

Sin embargo, el impacto de los resultados reseñados sobre los aprendizajes de los alumnos en el sistema escolar no tiene la progresión esperada ante los insumos incorporados.
La evidencia aportada por la comparación de los resultados SIMCE a lo largo de los 90 puede ser resumida en cuatro constataciones. Primero, que hay una tendencia consistente aunque leve, de incremento en los promedios nacionales en la primera mitad de la década, reduciendo así levemente las diferencias de logros entre establecimientos municipales y particulares pagados. Esta se estancó de 1996 a 2002 y la diferencia aumentó. Segundo, que la distribución social de los aprendizajes exhibe una distribución altamente estratificada e inequitativa, similar a la de 1990. Tercero, que las mejoras en rendimiento son mayores que las del promedio en el caso de las escuelas básicas que han sido objeto de programas focalizados como el P-900 o el Programa rural, lo que ha significado disminución de las brechas de rendimiento entre este alumnado - el más pobre - y el resto del país. Por último, que las diferencias de logros en el aprendizaje entre las distintas dependencias del sistema subvencionado (Municipal y Particular) son mínimas y no siempre favorables a la educación privada, cuando se comparan grupos socioeconómicos homogéneos. (OCDE, 2004, p. 39-40).

La síntesis expuesta en el informe de la Organización para la Cooperación y el Desarrollo Económicos-OCDE, permite formarse un panorama cierto del problema, pero es relevante hacer las siguientes puntualizaciones. La educación chilena avanza sistemática pero lentamente, siendo más relevante que el factor dependencia del establecimiento (si es público o privado) el factor socioeconómico de la familia, lo que confirma que la sociedad chilena es la segunda más desigual de América latina 
tras Brasil, y es una de las más desiguales del mundo (PNUD, 2003; BRUNNER; ELACQUA, 2003). En consecuencia el principal factor explicativo en los resultados escolares son los antecedentes socioeconómicos, variable que ha sido y sigue siendo dominante al extremo que relega otras -como dependencia- con aportes marginales (DONOSO; HAWES, 2002). Adicionalmente esta relación evidencia que la educación tiene un papel limitado en la reducción de la equidad y desigualdad. Lo que se refuerza en segundo lugar, pues el estancamiento de los resultados responde también al estancamiento sino aumento de la brecha de inequidad en la distribución del ingreso en Chile, lo cual si bien ha implicado cierta reducción de la pobreza, las grietas con los de mayores ingresos se incrementan (CHILE, 2004). Tercero, el sistema educacional chileno ha sido capaz de reintegrar a un conjunto de estudiantes que estaban fuera del sistema, los que en su gran mayoría corresponden a los sectores de mayor vulnerabilidad social, sin por ello bajar sus rendimientos generales, aspecto que no es menor pero que no ha sido del todo destacado, y aparece más como excusa ante quienes critican que no se avanza a gran velocidad que como elemento explicativo real.

De hecho son los resultados escolares del SIMCE como de las pruebas de comparación internacional TIMMS - incluyendo los resultados para el año 2003 -, y PISA lo que detonan el fin de esta etapa y el inicio de una 'crisis no resuelta hasta la fecha'.

Estos estudios revelaron que el sistema escolar estaba obteniendo bajos logros en comparación con los competitivos estándares de aprendizaje en el mundo. [...] mientras las bases del nuevo sistema escolar estaban ahora implementadas, las experiencias de aprendizaje estaban lejos de lo que requiere una soci- edad crecientemente integrada en un mundo globalizado y aún más exigente en términos de conocimiento y habilidades de las personas y organizaciones. (OCDE, 2004, p. 35).

Los resultados expuestos ratifican dos hipótesis. La primera que los logros de Chile no son buenos en ninguna estructura comparativa, es decir que los establecimientos escolares de elite social y económica del país no alcanzan logros comparables con los de sus pares de otras latitudes (confirmado incluso con la medición Timms del año 2003). Ello implica que el problema en Chile tiene una dimensión estructural importante y, que los establecimientos particulares, comparados con sus pares están significativamente más atrás, en consecuencia privatizar, no parece ser un camino a seguir, más aún si sus precios promedio (valor colegiatura) más que triplican el valor de la subvención, no obteniéndose resultados acordes a este diferencial de inversión. La segunda hipótesis en consideración es que en las pruebas internacionales de los países con mayor desigualdad social reproducen en parte importante su mayor desigualdad educativa (GARCÍA-HUIDOBRO; BELLEI, 2003, p. 46).

Los resultados expuestos en esta sección muestran que la calidad de la educación como materia pedagógicamente dominante de una reforma que ha cumplido un ciclo importante en materia de recuperar para el país-aunque experiencialmente sea irreversible para las personas- los estándares tradicionales de capital educativo, sin embargo está al debe en esta tarea de mejorar significativamente este ámbito. También queda en evidencia que esta temática de política educativa -la calidad- se asienta en el 
caso chileno sobre una base social extraordinariamente compleja, la desigualdad que se manifiesta en el ámbito social, económi$\mathrm{co}$, cultural y educativo. Aunque su tratamiento inicial correspondería a una política social, lo cierto es que se encuentra en el límite entre ambas, en razón fundamentalmente del rol que la educación cumple en este plano y de allí el papel que les compete a los gobiernos subnacionales.

\section{c) Dificultades en los procesos de gestión}

En esta dimensión se vislumbran una serie de dificultades de cierta complejidad, que responden a problemas de diseño de los procesos, a su implantación como a los recursos involucrados. Una de las dificultades mayores del sistema en materia de gestión se deba a que se combinan

[...] dos políticas de reforma coexistentes pero ideológicamente en conflicto. Una es la noción de que los mercados educacionales, con competencia entre escuelas, un alto grado de elección de los establecimientos educacionales por parte de los padres, y una administración privada de dichos establecimientos, proporcionan la mejor esperanza de eficiencia educacional y el rendimiento escolar más alto posible. La otra es la noción de que el gobierno central debe intervenir en el sistema educacional con una clara visión de lo que constituye una buena educación y cómo lograrla para asegurar que los estudiantes tengan la mayor oportunidad de aprender. (OCDE, 2004, p. 289).

El fenómeno identificado por el informe de la OCDE, en la práctica ha terminado de resolverse favorablemente hacia la primera política: el mercado, pues ésta visión es la que domina en materia de financiamiento y ordena las siguientes. El mercado es el agente ordenador y los gobierno subnacionales tiene un rol insignificante, tal como lo describe la misma Ley (LOCE) al respecto ${ }^{5}$, función que se ve minimizado por el papel centralista de la organización ministerial y de la reforma educativa en particular.

Sólo a partir de mediados de este año (2005) el sistema de financiamiento considera en mayor proporción las profundas y significativas diferencias de capital económico y social de la población escolar chilena. En los hechos hasta ahora ha implicado una postergación del servicio educativo 'a los más costosos de atender', dado que el sistema aporta un valor muy parecido para toda la población escolar (SAPELLI, 2003), en consecuencia atender a los grupos de mayor costo no es rentable, generándose los cambios en la matrícula que se han anotado (GONZÁLEZ, 2005). Es más, Hsieh y Urquiola (2002) atribuyen los mejores resultados escolares del sector particular subvencionado al desplazamiento de la población de mejores ingresos relativos hacia ese sector, es decir al propio capital social y económico de ese grupo, más que a la calidad misma de la educación,

El sistema de financiamiento a la demanda, estructurado por un pago proporcional a los días de asistencia promedio alumno/mes de un estudiante al establecimiento, ha dado origen a una serie de problemas y perversiones que el sistema ha incorporado para no colapsar. Tan es así

\footnotetext{
${ }^{5}$ Nos referimos a la Ley orgánica Constitucional de Enseñanza (LOCE) promulgada 3 días antes del término del Gobierno Militar, aunque posee enmiendas posteriores, parte sustantiva de su cuerpo doctrinario permanece regulando al sector, y en especial a los artículos 22 a 24 que otorgan atribuciones a nivel regional para sancionar algunas acciones.
} 
que en 1987 se tuvo que hacer un aporte significativo a los municipios para cancelar deudas históricas que eran impagables para evitar el colapso del sistema (JOFRÉ, 1988). El Gobierno democrático desde año 1990 en adelante ha mejorado substancialmente el valor de la subvención, ha creado subvenciones complementarias de diverso tipo (de ruralidad, de desempeño difícil, de escuelas pequeñas, y ahora de corrección socioeconómica) pero siempre en el racional operativo del mercado.

Las condiciones para que opere un 'mercado educacional' son complejas y difícilmente se cumplen en el sector. La segmentación creciente muestra que se generan submercados pues las condiciones de asimetría de información son muy elevadas, a parte que con el valor de la subvenciones se estimulaba un mercado que atendiera los alumnos rentables, eliminando a los más costosos, estimulando la selectividad, reduciendo la solidaridad intergeneracional, etc. problemas substanciales a los que un sistema educativo en sus diverso niveles debe atender (DONOSO; SCHMAL, 2002).

Un secundo foco de problemas se deriva del hecho que el Ministerio respectivo y los organismos desconcentrados no tienen las atribuciones para garantizar lo que la LOCE le manda (artículo $2^{\circ}$ del citado cuerpo legal). El Ministerio o tiene la posibilidad de intervenir a los sostenedores de establecimientos escolares, sean gobiernos subnacionales o particulares, sino en determinados casos, más bien macro-estructurales pero que no dicen relación directa con la función de calidad de la educación.

En el caso particular del sistema de subvenciones, el estado no tienen mecanismos de control eficientes - más allá de las obligaciones que se establecen para ciertos subsidios específicos - que permitan saber con precisión como los agentes educativos (sostenedores), utilizan los recursos entregados por el Estado, y por ende, no es posible conocer tan precisamente la rentabilidad social que genera la inversión pública en esta materia.

El ministerio, sea centralizada o descentralizadamente, al no disponer de estos instrumentos dependen de la buena voluntad de los agentes educacionales para cumplir con aquellas normativas que no sean expresamente obligatorias según la LOCE. Este fenómeno ha conducido a una creciente tecnocratización de las decisiones del Ministerio de Educación, reforzado porque los resultados en materia de logros en aprendizaje han sido menos positivos de lo esperado. Ello implica revisar la política de participación y de descentralización, que son indicadores de una sólida convicción democrática, aspectos que requieren una clara vocación de refuerzo para evitar las tentaciones tecnocráticas que surgen cuando los resultados no se van alcanzando según lo esperado.

El tercer foco de problemas derivado del anterior, es que no existe una visión de trabajo hacia y de los Gobiernos subnacionales que implique una sinergia operacional relevante. De hecho los Gobiernos regionales no tiene un rol operativo en esta materia sino que responden más bien a un criterio desconcentrador del aparato central, En consecuencia el sentido de su trabajo es responder como brazo "supervisor" del Gobierno central, pero no le compete la búsqueda de identidad subnacional, su estímulo y desarrollo. En contraposición a ello, los Gobiernos locales, que tiene un papel operativo, pueden asumir esta tarea 
y por ende su racional se diferencia del definido para el gobierno Regional. Esta situación se complejiza al no existir instancias formales, de carácter amplio, que convoque a los actores locales públicos y privados a la construcción y/ participación de un proyecto identitario en el ámbito del gobierno subnacional, lo que implica una gran debilidad de gestión que responde a un diseño político incompleto.

\section{Nuevas demandas y viejas respuestas de los Gobiernos subnacionales en Educación}

La Ley Orgánica Constitucional de Enseñan (LOCE) asigna algunas funciones a las entidades descentralizadas, de manera que en el plano regional le compete como tareas propias y no delegadas del nivel nacional, las materias vinculadas al reconocimientos de los establecimientos educacionales, como también a la pérdida de esta condición, muchas de las restantes funciones que asumen esas unidades subnacionales son delegadas por el gobierno nacional, y responden a criterios descentralizadores o de desconcentración. Por su parte al gobierno local le corresponde de manera irrenunciable - desde el año 1981 en adelante - la gestión de los establecimientos escolares, los docentes y los restantes recursos para el cumplimiento de esta función. Inicialmente la ley permitió a los municipios la creación de corporaciones orientadas a esta finalidad, estructura por la adoptaron menos del $20 \%$ de las casi trescientos cincuenta unidades de este tipo que hay en el país, asumiendo los restantes la gestión por la conformación de Departamentos de Administración de la Educación Municipal - DAEM.
Cualquiera sea la organización funcional que asuman los gobiernos subnacionales de nivel local, sus tareas son equivalentes y responden - en el caso del sector educación - a la necesidad de ofrecer educación a toda la población. Sin embargo la provisión del servicio educativo en el plano local enfrenta de manera permanente el desafío de distribuir las oportunidades educacionales en función del mérito del estudiante o bien por criterios de equidad o por una combinación de ambos. La forma cómo se resuelve esta temática genera una tensión no resuelta por el sistema educativo chileno, producto que en éste se mezclan los criterios de financiamiento de mercado vía demanda, con algunos basados en la oferta, que responden más a un estado de bienestar que a uno subsidiario.

Por otra parte, la competitividad por obtener resultados positivos en materia de aprendizaje de los estudiantes es un imperativo constante, con implicancias de significación sobre la demanda por matrículas y por ende en la asignación o captura de recursos financieros, fenómeno que ha hecho cada vez más compleja su papel en el plano de la política social con el que le corresponde en el ámbito de la política educativa. Esta situación se agudiza más por el hecho que Chile posee un sistema de medición de resultados escolar con gran validación social (el SIMCE), que si bien pondera las capacidades o aprendizajes por segmentos socioeconómicos, los resultados por mérito suelen ser dominantes, pese a que la teoría es pródiga y abundante respecto de la fuerte relación entre los resultados escolares con la estructura socioeconómica de las oportunidades y con redes sociales (NÚÑEZ; GUTIÉRREZ, 2004; MATTE, 2005; CORVALAN; ELACQUA, 2005; BEYER, 2005; MONTES, 2005). 
Complementariamente respecto de lo señalado esta tensión se reactiva, cuando la sociedad chilena ha definido como un derecho para toda persona la educación secundaria. De esta forma el componente "mérito" debería reducirse como factor operacional selectivo, pues al tratarse de un derecho implica que aquellos que sostienen el racional por mérito, deberían fundamentar con razones sólidas para justificarle por esa vía. Este conflicto pone en evidencia que aún no se comprende por los diversos actores educativos, institucionales y naturales que las reglas del sistema escolar han cambiado desde la competitividad de mercado al derecho para todos de una buena educación, esto demanda que los actores perciban los mismos objetivos sociales, lo cual no es del todo posible dado el sistema de financiamiento que existe. El sesgo pro acción positiva que debería presentarse en este caso no es tal (RAWLS, 1971, 1986). Lo que es complejo pues se debe reconocer y asumir a la sociedad como un cuerpo con grandes desigualdades que derivan en injusticias, lo que implica proponer y llevar a cabo acciones correctivas orientadas a reducir significativamente esa condición, para transformar el derecho a la educación en un acto positivo y real, donde la meritocracia no cabe. Asociado a ello el reconocimiento ha de transformarse en una política de Estado de la cual se deriven orientaciones explícitas e instrumentos adecuados para cerrar las brechas de desigualdad existentes que impiden transformar este derecho en la oportunidad de acceso a una educación de calidad según sus necesidades: la gestión en este caso es claramente obsoleta.
Esta situación amerita la revisión del sistema de subsidio por alumno implementado en Chile, dado que su forma de operar ha terminado excluyendo a los alumnos que demandan más costo, siendo entonces perverso respecto de la política educacional como un derecho. Si bien se han propuesto e implementado algunos correctores que apuntan en esta dirección, éstos empezarán a funcionar masivamente a partir del año 2006, por ende su impacto se dejará sentir más adelante. Ciertamente si bien estos instrumentos contribuirán a reducir el impacto excluyente del sistema de financiamiento, éste no solamente opera por esta vía. Los problemas de exclusión y segmentación se deben a que existe la posibilidad cierta en la educación particular, con y sin subvención, como también en algunos establecimientos municipales de seleccionar estudiantes por características significativas sea exámenes asociados a logros, calificaciones escolares, historial escolar, ingresos familiares, etc. Complementariamente también el sistema permite la selección ex post, que aunque menos frecuente en el ámbito público se emplea con cierta regularidad vía suspensión de estudios," término anticipado del año escolar, expulsión del establecimiento, etc.

En este marco, la estructuración de la gestión, tanto en materia de su rol, componentes y procesos involucrados en el accionar de los Gobiernos subnacionales, sean regionales o locales, responde a los criterios de descentralización asumidos por el Estado, que en lo fundamental hacen dependientes a estas entidades del financiamiento central para tomar sus decisiones, algo que en el pla- 
no municipal es determinante: de los 100 municipios más pobres dependen significativamente (más del $65 \%$ de sus ingresos) de los recursos nacionales para poder funcionar, lo que reduce su autonomía real (SUR PROFESIONALES CONSULTORES, 2003). La tónica dominante en este caso es gobiernos pequeños, con escasos recursos en todos los ámbitos y con unidades escolares reducidas, que no permiten generar aquellas economías de escalas asociadas a variables que inciden significativamente en la calidad educativa (GONZÁLEZ, 2005).

Esta situación se hace más problemática cuando los gobiernos locales no visualizan ni tampoco establecen pasos para una asociación eficiente con otros entes del territorio, para efectos de racionalizar sus estructuras de gestión, establecer políticas comunes, generar economías de escalas y promover una visión territorial a la que se incorporen los agentes privados que participan en el campo educacional provocando la sinergia necesaria.

\section{El desarrollo de la capacidad de gestión de los Gobiernos subnacionales en Educación}

El desarrollo de la capacidad de gestión de los gobiernos subnacionales implica visualizar varias dimensiones, una se refiere a los aspectos convencionales ligados a los procesos de gestión; pero emanan otros que provienen de la adecuación de las políticas nacionales, como finalmente el que corresponde a la elaboración de políticas propias (empode- ramiento) para su ámbito de gestión e influencia, el referido a los nexos de estas políticas con los gobiernos locales (lo que de paso implica revisar con mayor detenimiento estos aspectos en el plano local), el correspondiente a los mecanismos e instrumentos de gestión, incluyendo los sistemas de control interno y externo, incentivos, indicadores, los criterios de desempeño y otros elementos propios del tema en análisis.

\section{Aspectos convencionales de los procesos de gestión en este escenario}

En lo medular esta materia se refiere a cómo mejorar los procesos de gestión pública, sean en término de los tiempos que involucra, en la localización, en la atención y en los servicios o productos que se proveen.

La instalación de los procesos de gestión en los Gobiernos subnacionales es un fenómeno situado históricamente, que para el caso chileno, como país fuertemente centralizado, implica romper un circulo vicioso muy complejo relacionado con la posibilidad de experimentar y practicar procesos de descentralización y de desconcentración. Suele ocurrir que se argumenta en contra de este proceso debido a "los bajos resultados alcanzados por los Gobiernos subnacionales en determinadas tareas", sin mediar el hecho que no se dispone de experiencias en esas tareas y en muchas oportunidades de los recursos adecuados para resolverlas. Condición que no ha sido desarrollada -precisamente - debido a que no ha existido la oportunidad de practicar debidamente esta competencia. 
En el ámbito de la planificación, se ha dotado de instrumentos a los distintos niveles del sistema, en las comunas se cuenta con el PADEM y en el caso de los establecimientos está el Proyectos Educativos Institucionales - PEI, que se han transformado, en muchos casos, en meros ejercicios intelectuales, cuya finalidad y eficacia es de dudosa cuantía ${ }^{6}$; ya que no se cuenta con un marco regulador que vinculen este tipo de instrumentos con otras políticas orientadas a generar mayor sinergia, cómo sería, permitir la concursabilidad a Fondos Públicos en aquellas líneas de programas que estén vinculados explícitamente con los planes de desarrollo los distintos agentes educativos (escuelas o sistemas subnacionales).

Un segundo considerando emana de las propias limitaciones enumeradas por los funcionarios públicos chilenos que trabajan en Gobiernos subnacionales, algunas de ellas han sido recogidas en estudios sobre la materia (GILBERT, 2004):

a. Cargos claves de Gobiernos subnacionales responden principalmente a la autoridad central.

b. Desempeño de muchas funciones con pocas atribuciones resolutivas.

c. Existencia de muchas funciones de intermediación y coordinación sin recursos legales y financieros para cumplir esa tarea.

d. La evaluación de desempeño no refuerza una acción positiva. Se nivelan rendimientos dispares.

e. Existencia de 'castas' de funcionarios, diferenciados según contrato de estabilidad o no. f. Escasa comunicación en la organización entre líderes y operadores, reforzada por cuoteos políticos y por visiones del cambio 'desde arriba'.

g. Valoración de la rutina, castigo al riesgo, escaso margen a la innovación.

Uno de los problemas cruciales que revelan estas enumeraciones, es la incapacidad a nivel de Gobiernos subnacionales por pensar y actuar en una proyección de largo plazo. Esta situación no es de fácil resolución, dado que el amenos en el plano regional las autoridades responden al Gobierno central y al no ser elegida por votación universal democrática no poseen la legitimación para convocar un proceso de desarrollo que podría en alguna medida entrar en conflicto con la autoridad nacional. Esta situación reduce su peso y deja a los Gobiernos locales con la posibilidad de asumir esta tarea, pero con un engranaje territorial que "coordina" sin mayor involucramiento en la dimensión territorial.

En general los mejoramientos en los procesos de gestión asumieron "cumplir más tareas con menos recursos financieros, humanos y de tiempo". Esta máxima impuesta en una economía ortoxamente de mercado ha sido extremada hasta límites que no tienen cabida. Plantearse el mejoramiento de la gestión pública en nuestro caso es ese axioma ya imposible y quizás ello de cuenta del estancamiento del proceso de modernización de la gestión pública, incluyendo educación, que requiere comprender que hacer más demandas, después de cierto límite de eficiencia, implica mayores recursos (GILBERT, 2004).

\footnotetext{
${ }^{6}$ Entre algunas de las debilidades del PADEM se encuentran su utilización más como un instrumento de planificación presupuestaria
} que como una herramienta para la gestión técnico pedagógica (RACZYNSKI; SERRANO, 2001, p. 447). 
Por otra parte, el sistema educativo debería establecer a través de las políticas adecuadas, los mecanismos de incentivos que resguarden los objetivos de bien público asociados a la educación. Si embargo, como los señalan Raczynski y Serrano (2001, p. 433):

El dilema es el clásico de los modelos de agente principal. Como señala González (1998), el Estado no tiene la Certeza de que sean sus incentivos (las subvenciones, el SNED, etc.) los que orientan el trabajo del agente. Tampoco pueden verificar la eficiencia y eficacia de sus acciones. el principal Estado está muy lejos de los agentes trabajadores de la escuela.

\section{Adecuación de las políticas y diseño de mecanismos de gestión en los Gobiernos subnacionales}

Dada la estructura constitucional y productiva del país se entiende que más que diseñar en el pleno sentido del término políticas propias para cada Gobierno subnacional, es más factible y pertinente reforzar la adecuación significativa de las políticas y su diseño al marco de cada entidad subnacional, tarea que en los hechos es uno de los principales desafíos nacionales de los próximos años, no solamente por las obvias e importantes implicancias para su gestión en pro de mejorar la implementación de las mismas, sino porque impone competencias a los Gobiernos subnacionales que hasta ahora han sido escasamente utilizadas como es la adecuación, creativa y pertinente de las políticas y su ulterior diseño y adaptación de los mecanismos de gestión. Visto desde la gestión la capacidad de implementar nuevas iniciativas marcadas por una autonomía mayor.

Por otra parte esta visión implica el fortalecimiento de la indisoluble relación que debe existir entre el campo político con el de la gestión educacional, hasta hoy débilmente desarrollado más aún en los gobiernos subnacionales que tienen un rol marginal en el diseño político y secundario en la gestión, Este proceso de complementación - de existir condiciones mínimas para su puesta en práctica ${ }^{7}$ - es operacionalmente más fácil que acontezca en estas unidades de Gobierno (subnacionales).

\section{Fortalecimiento de la educación pública como opción de desarrollo democrático}

El desarrollo y fortalecimiento de la educación pública se transforma en una tarea de sustentación para una sociedad diversa, con una democracia fuerte que se evidencia en un proyecto país compartido, construido desde las identidades locales en una perspectiva global.

Lo público posee nuevas dimensiones tanto en su conceptualización como en su aplicación. Por una parte ha perdido significación quién provee el servicio respecto de los principios y criterios operacionales del mismo, aunque ahora adquiere mayor significación la distinción respecto del impacto de estas acciones sobre los bienes públicos netos (no competitivos e indivisibles), los semi públicos (competitivos pero que implican un

\footnotetext{
${ }^{7}$ Las que no tienen que ver con lo legal solamente sino con la disponibilidad de recursos financieros y con el establecimiento de metas de gestión que no sean impuestas desde el Gobierno nacional.
} 
beneficio colectivo neto -sin excluir el plano privado), y los bienes privados. Ello se traduce en que se requiere mayor claridad y mejor identificación de los fundamentos para el diseño, análisis e implementación de las políticas educativas en referencia a su impacto en los componentes sociales y públicos en general, es decir en sus aportes finales a la igualdad, equidad y justicia social.

Adicionalmente, ciertas evidencias de los temas en conflicto, que hacen relevante el énfasis de lo público y de la educación pública, se refieren precisamente al fortalecimientos de los procesos de desarrollo local y regional, que necesitan desplegar y vigorizar la identidad de los habitantes de cada territorio, para lo cual la educación pública tiene un papel indiscutido producto de su definición esencial de aquellos elementos comunes y propios de todos.

Esta función se debe a diversas razones; inicialmente porque este segmento institucional es el que tiene la mayor responsabilidad por educar a la población, pero fundamentalmente debido a que las cambios en las políticas educacionales enfatizados por la privatización de las acciones y su focalización, han implicado que el sector público local atienda de manera preferente a la población más pobre del país y, además, debido a que la política de focalización -definidas como el área clave de lo público en el enfoque neoliberal del desarrollo- han terminado generando grupos homogéneos, excluyentes de hecho de la diversidad de los proyectos educativos nacionales,

La política de exclusión ha generado una "equidad segregada", es decir: agrupar los más iguales con los más iguales, o los menos desiguales con los menos desiguales, que es el contrasentido de una política pública basada en la diversidad, en su reconocimiento y respeto, para plantearse desde esta visión lo común, lo compartido. El rescate de este componente es un factor clave, que es producto de los instrumentos de gestión definidos que demandan nuevas competencias en capacidad de diseño y producción de políticas y de sus estrategias de implementación y gestión.

En el caso chileno también ha contribuido a estas nuevas condiciones el hecho que en términos cuantitativos, como señaláramos anteriormente- la matrícula de educación pública desde hace unos años a la fecha se distribuye casi por partes iguales entre los municipios y los sostenedores privados, dando cuenta de una realidad para el diseño de política y fundamentalmente para su gestión, se asume - por inercia - al sector municipal como casi el único oferente de educación pública, si bien los 350 municipios son el operador principal, los privados también lo son, aunque el número de operadores es claramente mayor.

\section{Mecanismos de gestión eficientes y consistentes}

El análisis de estos aspectos se refiere a un conjunto de mecanismos que teniendo distinto punto de origen convergen en la búsqueda de una gestión eficiente que no signifique ahondar los problemas actuales ni renunciar a los principios claves que sustentan la gestión pública, sino por el contrario, desde esta perspectiva abordables consistentemente.

\section{a) Instrumentos de política social instalados en el sistema educacional}

Desde inicios de los años 90', con el retorno de la democracia, la educación ha recobrado protagonismo y relevancia 
social, insertándose nuevamente como un sector relevante de política pública. En razón de esta condición y de su cobertura territorial, se implementan muchas políticas sociales en el campo educacional, en la escuela, sin diferenciarse del todo de las políticas educacionales, usando a los docentes para esa finalidad. Esta trama: "Política Pública - Política Social Política Educacional", da cuenta de un conjunto de relaciones que tienen incidencias mutuas, estableciendo un nuevo escenario en el cual se asientan los debates sobre el diseño y gestión de las políticas educacionales a nivel de los Gobiernos subnacionales.

En tal sentido, el actual desarrollo del país demanda que los Gobiernos subnacionales privilegien a los docentes en las tareas educativas y mediante otros mecanismos de gestión apliquen las políticas sociales que consideran a la escuela como eje, incluyendo la alimentación escolar, y otras 8 .

\section{b) Mecanismos eficientes de los Gobiernos subnacionales para gesti- onar la educación en su ámbito terri- torial}

En consonancia con lo señalado, uno de los problemas ejes de la gestión heredados de la reforma de 1981, es la falta de instrumentos eficientes en el campo educacional para el Gobierno nacional y con mayor relevancia aún para los gobiernos subnacionales, para generar una relación productiva entre todos (agentes Municipales y sostenedores privados)
Simplificadamente, el problema puede definirse en términos que el Ministerio ni sus operadores subnacionales disponen de los instrumentos que le permitan ejercer en plenitud su autoridad en referencia a los sostenedores. Es decir, su responsabilidad excede los instrumentos que se dispone para poder hacerse cargo de los resultados educacionales, como en su mandato constitucional lo señala.

Este punto ha entorpecido significativamente el desarrollo educativo, tanto en el plano regional como local. Mientras la situación legal se trata de resolver, creemos importante hacer conciencia del problema en los actores más relevantes y, por la vía del convencimiento demostrar las bondades de su resolución e identificar caminos viables y pertinentes para ello, ya que esta situación enfrentada localmente en un formato "caso a caso", corresponde a una escala que hace mucho más manejable el problema que en una opción de debate nacional.

\section{c) La formación de los recursos humanos es disfuncional}

Dos aspectos se vinculan con lo señalado: el primero de ellos asume que si bien los problemas definidos no son privativos de la situación chilena, sino por el contrario se trata de una temática asimilable a otras realidades latinoamericanas, la formación de los recursos humanos para la gestión y diseño de políticas educativas a nivel de Gobiernos subnacionales, sigue la tónica de la mirada desde el centro, en este plano se requiere reorientar su formación y a partir de ello la innovación y pertinencia en los mecanismos que diseñen.

\footnotetext{
${ }^{8}$ En los niveles socioeconómicos medios y altos los docentes no asumen esta función. En los niveles más descendidos los maestros, cuyo rol educativo en ese medio es más relevantes pues las fuentes alternativas de educación son menores deben dedicar tiempo a cumplir tareas sociales, las que siendo importante, le restan tiempo a las educativas, con el consecuente impacto en las evaluaciones de resultados de aprendizaje de los estudiantes, pues éstas no ponderan debidamente las "tareas sociales" que realizan los maestros de las escuelas que atienden a la población más necesitada.
} 
El segundo aspecto se relaciona con el desafío de asumir desde la educación públi$\mathrm{ca}$, con instrumentos de gestión que no impliquen recurrir a las herramientas convencionales del área privada, a saber: selección de estudiantes, traspaso de costos a los privados, aumento de precios y otros; haciéndose cargo de aquella población que no opera con los privados y que esencialmente corresponde a la de mayores carencias de capital social, cultural, educacional y económico, y a partir de esta realidad, buscar soluciones consistentes y coherentes con el principio de equidad y de justicia que debe subyacer a la implementación de la política de educación pública, sin renunciar a la calidad como herramienta para "romper" los círculos de descapitalización que se han definido.

De igual forma implica comprender al menos para el caso chileno - que los modelos de gestión privada de la educaci- ón no han mostrado bondades tan superiores al del sector público (consistentes con una inversión que en promedio es 4 ○ 5 veces superior) menos aún si se compara sus resultados respecto de los estándares internacionales, es decir allí el desafío es mayor, pues claramente no son el camino posible a seguir por la educación pública, sea por razones de costo, como finalmente por los resultados alcanzados que son más bajos y no responden al de establecimientos pares de otras latitudes.

En síntesis, los procesos de formación han de enfatizar la articulación de los enfoques de nivel nacional con el subnacional en lo regional y local, perspectiva que busca en lo operacional conectar en forma eficiente la capacidad de pensar y saber hacer en materia de diseño de políticas y procesos de gestión para los gobiernos subnacionales coherentes con las propuestas nacionales.

\section{Referências}

BEYER, H. Hablando de mitos sobre la educación en Chile. Diario el Mercurio de Santiago, Santiago, Chile, p. 2, 17 mayo 2005. Cuerpo A.

BEYER, H.; EYZAGUIIIRRE, B.; FONTAINE, L. La reforma educativa chilena. In: HEVIA, R. (Ed.). La educación en Chile hoy. Santiago, Chile: Ediciones Universidad Diego Portales, 2003. p. 179-202.

CARO, J. El contexto histórico de la descentralización. In: VERGARA, J.; VON BAER, E. En la frontera del desarrollo endógeno. Temuco, Chile: Ediciones Universidad de la Frontera: CIDER, 2004. p. 413-446.

CHILE. Ministerio de Educación. Indicadores de la educación en Chile 2002. Santiago, Chile, 2002.

CHILE. Ministerio de Planificación. Ministerio de Educación. Educación y pobreza: resultados de la encuesta Casen 2003. Santiago, Chile, 2004. Disponível em: $<$ www.mideplan.cl/casen >. Acesso em: 27 oct. 2004.

CORVALÁN, J.; ELACQUA, G. Mitos sobre la educación en Chile. Diario el Mercurio de Santiago, Santiago, Chile, p. 2, 14 mayo 2005. Cuerpo A. 
COX, C. Las políticas educacionales de Chile en las últimas dos décadas del siglo XX. In: COX, C. (Ed.). Políticas educacionales en el cambio de siglo: la reforma del sistema escolar en Chile. Santiago, Chile: Editorial Universitaria, 2003. Capítulo I, p. 19-114.

DONOSO, S.; HAWES, G. Eficiencia escolar y diferencias socioeconómicas: a propósito de los resultados de las pruebas de medición de la Calidad de la Educación en Chile. Educação e Pesquisa, São Paulo, v. 28, n. 2, p. 25-40, 2002.

DONOSO, S.; SCHMAL, R. Elementos para definir una política de financiamiento de la educación pública. In: Pensamiento Educativo: revista de la Pontificia Universidad Católica de Chile, Facultad de Educación, Santiago, Chile, n. 31, p. 256-282, 2002.

GARCÍA-HUIDOBRO, J. E.; BELLEI, C. Desigualdad educativa en Chile. Santiago, Chile: Universidad Alberto Hurtado, 2003. 62 p.

GARCÍA-HUIDOBRO, J. E.; COX, C. La reforma educacional chilena 1990 -1998: visión de conjunto. In: GARCÍA-HUIDOBRO, J. E. (Ed.). La reforma educacional chilena. Madrid: Editorial Popular, 1999. Capítulo I, p. 7-46.

GILBERT, J. Desafíos de la gestión pública regional. In: VERGARA, J.; VON BAER, E.. En la frontera del desarrollo endógeno. Temuco, Chile: Ediciones Universidad de la Frontera: CIDER, 2004. p. 447-466.

GONZÁLEZ, P. Estructura institucional, recursos y gestión en el sistema escolar chileno. In: COX, C. (Ed.). Políticas educacionales en el cambio de siglo: la reforma del sistema escolar en Chile. Santiago, Chile: Editorial Universitaria, 2003. p. 597- 660.

GONZÁLEZ, P. La igualdad educativa, el financiamiento vía subvenciones y la administración privada de la educación, elementos para la discusión. In: SEMINARIO INTERNACIONAL SOBRE POLITICAS EDUCATIVAS Y EQUIDAD, 2004, Santiago. Anais ... Santiago de Chile: Fundación Ford: Unesco: Unicef: Departamento de Educación, Universidad Alberto Hurtado, 2005. p. 247-270.

HSEIH, C.; URQUIOLA, M. When school competes, how they compete?: an assessment of Chile's nation wide school voucher program. Washington: World Bank's Development Group, 2002.

JOFRÉ, G. Subvenciones en educación. Estudios Públicos: revista del Centro de Estudios Públicos, Santiago, Chile, n. 32, p. 31-55, 1988.

LASSIBILLE, G.; Navarro, M. L. Manual de economía de la educación: teoría y casos prácticos. Madrid: Ediciones Pirámide, 2004.

MATTE, P. Mitos sobre la educación en Chile. Diario el Mercurio de Santiago, Santiago, Chile, p. 2, 27 mayo 2005. Cuerpo A. 
MONTES, T. Mitos sobre la educación en Chile. Diario el Mercurio de Santiago, Santiago, Chile, p. 2, 24 mayo 2005. Cuerpo A.

NÚÑEZ, I. El profesorado, su gremio y la reforma de los años noventa: presiones de cambio y evolución en la cultura docente. In: COX, C. (Ed.). Políticas educacionales en el cambio de siglo: la reforma del sistema escolar en Chile. Santiago, Chile: Editorial Universitaria, 2003. Capítulo I, p. 455-518.

NÚÑEZ, J.; GUTIÉRREZ, R. Clasismo, discriminación y meritocracia en el mercado laboral: el caso de Chile. Santiago, Chile: Departamento de Economía, Universidad de Chile, 2004. Mimeografado.

OCDE (Chile). Revisión de las políticas nacionales de educación: organización para la Cooperación y el Desarrollo. París, 2004. 305 p.

PNUD. Desarrollo humano en Chile 2002. Santiago, Chile, 2003.

RACZYNSKI, D.; SERRANO, C. Descentralización nudos críticos. Santiago, Chile: Corporación de Investigaciones Económicas para Latinoamérica (CIEPLAN), Asesorías para el Desarrollo, 2001.

RAWLS, J. Justicia como equidad. Madrid: Editorial Universitaria Tecnos, 1986.

RAWLS, J. Teoría de la justicia. Madrid: Editorial Universitaria Tecnos, 1971.

ROSSANVAlLON, P. La Crisis del Estado de Providencia. Madrid: Editorial Civita, 1995.

SAPELLI, C. Introducción: la economía de la educación y el Sistema Educativo Chileno. Cuadernos de Economía, Santiago, Chile, n. 118, p. 281-296, 2002.

STIGLITZ, J. La economía del sector público. Madrid, España: Antonio Bosch Editor, 2000.

SUR PROFESIONALES CONSULTORES. SUBSECRETARIA DE DESARROLLO REGIONAL Y ADMINISTRATIVA (SUBDERE). Estudio diagnóstico línea de base para los 100 municipios con menores recursos del país: Programa de Fortalecimiento Institucional Municipal (PROFIM). Santiago, Chile, 2003.

TOMASSINI, L.; ARMIJO, M. Reforma y modernización del Estado. Santiago, Chile: Lom Editores, 2002.

Recebido: 03/07/2006

Aceito para publicação em: 17/08/2006 


\section{Cuadros y tablas}

Los Cuadros N's 1 y 2 presenta la misma información para el año 2000 y 1990. En una década se aprecia: (i) Una tendencia hacia una mayor concentración de los estudiantes de los deciles más bajos en el sistema municipal, y (ii) una mayor concentración de los más altos en el sistema particular pagado.

\section{CUADRO 1}

Distribución de la matrícula por dependencia y decil de ingresos de las familias 2000

\begin{tabular}{|c|c|c|c|c|c|c|c|}
\hline \multirow{3}{*}{$\begin{array}{c}\text { Decil de } \\
\text { ingreso } \\
\text { autónomo }\end{array}$} & \multicolumn{6}{|c|}{ DEPENDENCIA } & \multirow[b]{3}{*}{ Total } \\
\hline & \multicolumn{2}{|c|}{ Municipal } & \multicolumn{2}{|c|}{ Part. Subvencionado } & \multicolumn{2}{|c|}{ Part. Pagado } & \\
\hline & $\begin{array}{c}\% \\
\text { matricula }\end{array}$ & $\begin{array}{c}\text { Proporción } \\
\text { población } \\
\text { decil }\end{array}$ & $\begin{array}{c}\% \\
\text { matricula }\end{array}$ & $\begin{array}{c}\text { Proporción } \\
\text { población } \\
\text { decil }\end{array}$ & $\begin{array}{c}\% \\
\text { matricula }\end{array}$ & $\begin{array}{c}\text { Proporción } \\
\text { población } \\
\text { decil }\end{array}$ & \\
\hline 1 & 20,4 & 1,4 & 9,9 & 0,7 & 1,2 & 0,1 & 15,1 \\
\hline 2 & 19,6 & 1,3 & 11,4 & 0,8 & 1,4 & 0,1 & 15,1 \\
\hline 3 & 16,0 & 1,2 & 13,0 & 0,9 & 1,6 & 0,1 & 13,8 \\
\hline 4 & 12,2 & 1,1 & 0,9 & 1,0 & 1,7 & 0,2 & 10,9 \\
\hline 5 & 10,4 & 1,0 & 13,1 & 1,2 & 3,9 & 0,4 & 10,8 \\
\hline 6 & 7,7 & 0,9 & 12,0 & 1,3 & 3,8 & 0,4 & 9,0 \\
\hline 7 & 5,7 & 0,8 & 9,8 & 1,4 & 4,6 & 0,6 & 7,1 \\
\hline 8 & 4,2 & 0,6 & 9,7 & 1,4 & 12,4 & 1,8 & 6,9 \\
\hline 9 & 2,5 & 0,4 & 7,0 & 1,2 & 23,8 & 4,1 & 5,9 \\
\hline 10 & 1,2 & 0,2 & 3,1 & 0,6 & 45,6 & 8,1 & 5,6 \\
\hline Total & 100,0 & 1,0 & 100,0 & 1,0 & 100,0 & 1,0 & 100,0 \\
\hline
\end{tabular}

Fuente: González (2005). 


\section{CUADRO 2}

Distribución de la matrícula por dependencia y decil de ingresos de las familias 1990

\begin{tabular}{|c|c|c|c|c|c|c|c|}
\hline \multirow{3}{*}{$\begin{array}{l}\text { Decil de } \\
\text { ingreso }\end{array}$} & \multicolumn{6}{|c|}{ DEPENDENCIA } & \multirow[b]{3}{*}{ Total } \\
\hline & \multicolumn{2}{|c|}{ Municipal } & \multicolumn{2}{|c|}{ Part. Subvencionado } & \multicolumn{2}{|c|}{ Part. Pagado } & \\
\hline & $\begin{array}{c}\% \\
\text { matricula }\end{array}$ & $\begin{array}{c}\text { Proporción } \\
\text { población } \\
\text { decil }\end{array}$ & $\begin{array}{c}\% \\
\text { matricula }\end{array}$ & $\begin{array}{c}\text { Proporción } \\
\text { población } \\
\text { decil }\end{array}$ & $\begin{array}{c}\% \\
\text { matricula }\end{array}$ & $\begin{array}{c}\text { Proporción } \\
\text { población } \\
\text { decil }\end{array}$ & \\
\hline 1 & 20,9 & 1,2 & 12,7 & 0,7 & 2,2 & 0,1 & 16,9 \\
\hline 2 & 16,8 & 1,2 & 11,0 & 0,8 & 2,0 & 0,1 & 14,1 \\
\hline 3 & 14,7 & 1,2 & 11,7 & 0,9 & 1,5 & 0,1 & 12,7 \\
\hline 4 & 11,9 & 1,1 & 11,8 & 1,1 & 2,6 & 0,2 & 11,2 \\
\hline 5 & 9,5 & 1,0 & 10,7 & 1,1 & 2,8 & 0,3 & 9,4 \\
\hline 6 & 8,5 & 0,9 & 11,4 & 1,2 & 7,0 & 0,8 & 9,3 \\
\hline 7 & 6,0 & 0,9 & 9,1 & 1,3 & 5,9 & 0,8 & 7,0 \\
\hline 8 & 5,5 & 0,8 & 9,3 & 1,3 & 9,7 & 1,4 & 7,0 \\
\hline 9 & 3,9 & 0,6 & 6,9 & 1,1 & 22,5 & 3,6 & 6,3 \\
\hline 10 & 2,2 & 0,4 & 5,5 & 0,9 & 43,7 & 7,1 & 6,2 \\
\hline Total & 100,0 & 1,0 & 100,0 & 1,0 & 100,0 & 1,0 & 100,0 \\
\hline
\end{tabular}

Fuente: González (2005).

\section{CUADRO 3}

Decil socioeconómico establecimiento y decil del alumno (Simce 2003, 2do medio)

\begin{tabular}{|c|c|c|c|c|c|c|c|c|c|c|c|}
\hline \multirow{2}{*}{$\begin{array}{c}\text { Decil } \\
\text { establecimiento }\end{array}$} & \multicolumn{10}{|c|}{ Decil del alumno } & \multirow[t]{2}{*}{ Total } \\
\hline & 1 & 2 & 3 & 4 & 5 & 6 & 7 & 8 & 9 & 10 & \\
\hline 1 & 33,4 & 27,2 & 14,8 & 8,1 & 6,5 & 4,7 & 2,5 & 1,7 & & & 100,0 \\
\hline 2 & 20,2 & 21,2 & 17,6 & 12,5 & 10,3 & 7,6 & 5,3 & 2,8 & 1,8 & & 100,0 \\
\hline 3 & 13,6 & 15,4 & 15,4 & 15,3 & 13,3 & 10,9 & 8,2 & 4,5 & 2,7 & & 100,0 \\
\hline 4 & 9,0 & 11,0 & 13,5 & 14,0 & 14,3 & 13,0 & 11,8 & 7,6 & 4,7 & 1,2 & 100,0 \\
\hline 5 & 5,0 & 7,1 & 9,1 & 12,2 & 14,8 & 15,1 & 15,1 & 11,7 & 8,0 & 1,9 & 100,0 \\
\hline 6 & 2,6 & 3,6 & 5,2 & 8,1 & 10,2 & 13,7 & 17,3 & 18,4 & 15,6 & 5,1 & 100,0 \\
\hline 7 & 1,1 & 1,7 & 2,3 & 3,9 & 5,6 & 9,3 & 15,5 & 22,7 & 25,9 & 11,9 & 100,0 \\
\hline 8 & & & & 1,8 & 2,4 & 4,7 & 9,3 & 20,4 & 33,8 & 25,5 & 100,0 \\
\hline 9 & & & & & & 1,3 & 2,0 & 8,3 & 28,1 & 58,4 & 100,0 \\
\hline 10 & & & & & & & & 1,4 & 8,0 & 89,9 & 100,0 \\
\hline
\end{tabular}

Fuente: González (2005). 